\title{
MicroRNA-18a promotes proliferation and metastasis in hepatocellular carcinoma via targeting KLF4
}

\author{
Li Liu ${ }^{1, *}$, Xun Cai ${ }^{2, *}$, Enqiang Liu ${ }^{3}, X_{i a}$ Tian $^{4}$ and Chuan Tian ${ }^{4}$ \\ ${ }^{1}$ Department of Medicine \& Appliance, Yunyan District Market Supervision and Administration Bureau, Guizhou 550001, \\ China \\ ${ }^{2}$ Department of Oncology, Shanghai General Hospital, Shanghai Jiaotong University School of Medicine, Shanghai 200080, \\ China \\ ${ }^{3}$ Department of Oncology, Qianjiang Central Hospital of Chongqing Municipality, Chongqing 409000, China \\ ${ }^{4}$ Department of Nuclear Medicine, Guizhou Provincial People's Hospital, Guizhou 550000, China \\ *These authors have contributed equally to this work
}

Correspondence to: Chuan Tian, email: teechuan2015@126.com

Keywords: miR-18a, KLF4, p21, hepatocellular carcinoma

Received: March 22, $2017 \quad$ Accepted: June 19, $2017 \quad$ Published: July 17, 2017

Copyright: Liu et al. This is an open-access article distributed under the terms of the Creative Commons Attribution License 3.0 (CC BY 3.0), which permits unrestricted use, distribution, and reproduction in any medium, provided the original author and source are credited.

\section{ABSTRACT}

MicroRNAs (miRNAs) are short, non-coding and endogenous RNAs that played as important roles in the proliferation and metastasis of tumors. In this study, we determined the role of $\mathbf{m i R - 1 8 a}$ in the regulation of HCC cell motility. We showed that miR-18a expression was upregulated in human HCC tissues and cell lines. Moreover, Elevated expression of miR-18a promoted the HCC cell proliferation and migration. KLF4 was identified as a direct target of miR-18a in HCC cells. Furthermore, overexpression of KLF4 attenuated the effects of miR-18a on the regulation of HCC cell motility. The expression of KLF4 was negatively associated with the expression of miR-18a expression in HCC tissues. We also showed that the cell cycle inhibitor p21 was aberrantly downregulated in HCC cells, whereas this inhibition was reversed by $\mathbf{m i R - 1 8 a}$ inhibitor. These data indicated that miR-18a may play a positive role in hepatocellular carcinoma by promoting the proliferation and migration of HCC cells through targeting KLF4 as well as downstream p21.

\section{INTRODUCTION}

Hepatocellular carcinoma (HCC) is one of the most frequent and most lethal types of cancer worldwide with hardly any effective treatment available thus far $[1,2]$. So far, early detection, surgical resection and gene therapy are the major treatment approaches for HCC [3]. Despite significant improvements in diagnostic method and surgical therapy, the cure rate of $\mathrm{HCC}$ is very low. Hence, knowledge about the molecular mechanisms underlying HCC progression is an urgent need to improve the understanding of, and therapeutic strategies for, human HCC.

MicroRNAs (miRNAs) are a type of short, noncoding and endogenous RNAs that inhibit the protein coding genes expression through partial complementary binding to the 3'-UTR of mRNAs [4]. Accumulating evidence suggests that the dysregulation of miRNAs is involved in the pathogenesis of multiple human diseases [5-7]. In cancer, Ectopic regulation of miRNA expression has been reported widely and proven to be associated with cancer progression in glioma, metastatic prostate cancer, hepatocellular carcinoma, and others [8, 9]. Various studies also reported the differential expression of miRNAs in patients with hepatocellular carcinoma, including miR-135a, miR-33a, miR-320a, miR-122, and miR-31 [10-14].

Dysregulation of the miR-18a family expression has been detected in various cancers and was proven to be correlated with the biological mechanism of tumor development [15]. miR-18a was found to target the ESR1 
gene, which encodes for the estrogen receptor $\alpha(\operatorname{ER} \alpha)$ protein. The functional study of the effect of increased levels of miR-18a on both ligand-stimulated transcriptional activation and cell proliferation activity of $\mathrm{ER} \alpha$ further supported its involvement in regulating ER $\alpha$ 's functions [16]. In HCC, miRNA-18a was found to be significantly elevated and might be a potential screening biomarker for hepatocellular carcinoma [17]. However, the regulatory mechanism of miR-18a in HCC progression is still unknown.

Krüppel-like factor 4 (KLF4), a zinc-finger transcription factor, functions as a tumor suppressor or an oncogene. It plays an important role in cell proliferation and metastasis by regulating the expression of a number of downstream target genes [18]. Accumulating clinical, experimental and mechanistic evidence suggests that KLF4 functions as a tumor suppressor in various types of cancer, including HCC [14]. However, how KLF4 expression is decreased in the progression of HCC is still not well known.

In this study, we found that KLF4 is a potential direct target of miR-18a with a binding site in the 3'-UTR and investigated the role of $\mathrm{miR}-18 \mathrm{a}$ in regulating hepatocellular carcinoma cell proliferation and migration. miR-18a was found to be significantly upregulated in HCC and promotes hepatocellular carcinoma cell motility by inhibiting KLF4. Identification of this mechanism might provide to be a novel understanding and therapeutic approach for HCC.

\section{RESULTS}

\section{miR-18a expression was upregulated in human HCC tissues and cell lines}

We first investigated the expression levels of miR-18a in sample tissues of patients with hepatocellular carcinoma to determine the role of miR-18a in HCC.
As shown in Figure 1A, miR-18a was expressed at low levels in the adjacent normal liver tissues, while it was significantly upregulated in the liver cancer tissues.

Furthermore, we investigated the expression of miR-18a in human HCC cell lines Hep3B, Bel-7402, Huh7 and SK-hep-1. Compared to the normal liver cell LO2, miR-18a expression was upregulated in the Hep3B, Bel-7402, Huh7 and SK-hep-1 cells to different extents (Figure 1B). Taken together, these data suggest that miR18 a may play a positive role in the regulation of human HCC progression.

\section{miR-18a promotes the proliferation and migration of HCC cell lines}

We then introduced miR-18a mimic and inhibitor to determine the possible effects of miR-18a on the proliferation and migration of human hepatocellular carcinoma cells in vitro. Herein, the Hep3B and Bel7402 cell lines were chosen as the cell models according to the difference of miR-18a expression. The efficiency of miR-18a mimic and inhibitor was confirmed by RTPCR. Compared with the control miRNA, the miR-18a expression was significantly enhanced by the mimic but reduced by the inhibitor in both Hep3B and Bel-7402 cell lines (Figure 2A).

A CCK-8 assay was performed to examine the effect of miR-18a on the proliferation of Hep3B and Bel-7402 cells. As seen in Figure 2B, miR-18a mimic transfection remarkably increased the proliferation of both Hep3B and Bel-7402 cells compared with the control group. On the contrary, the proliferation capacity of these two cell lines was significantly restrained by miR-18a repression induced by inhibitor. We also confirmed the alteration of Hep3B and Bel-7402 cells migration using Transwell assay. Results
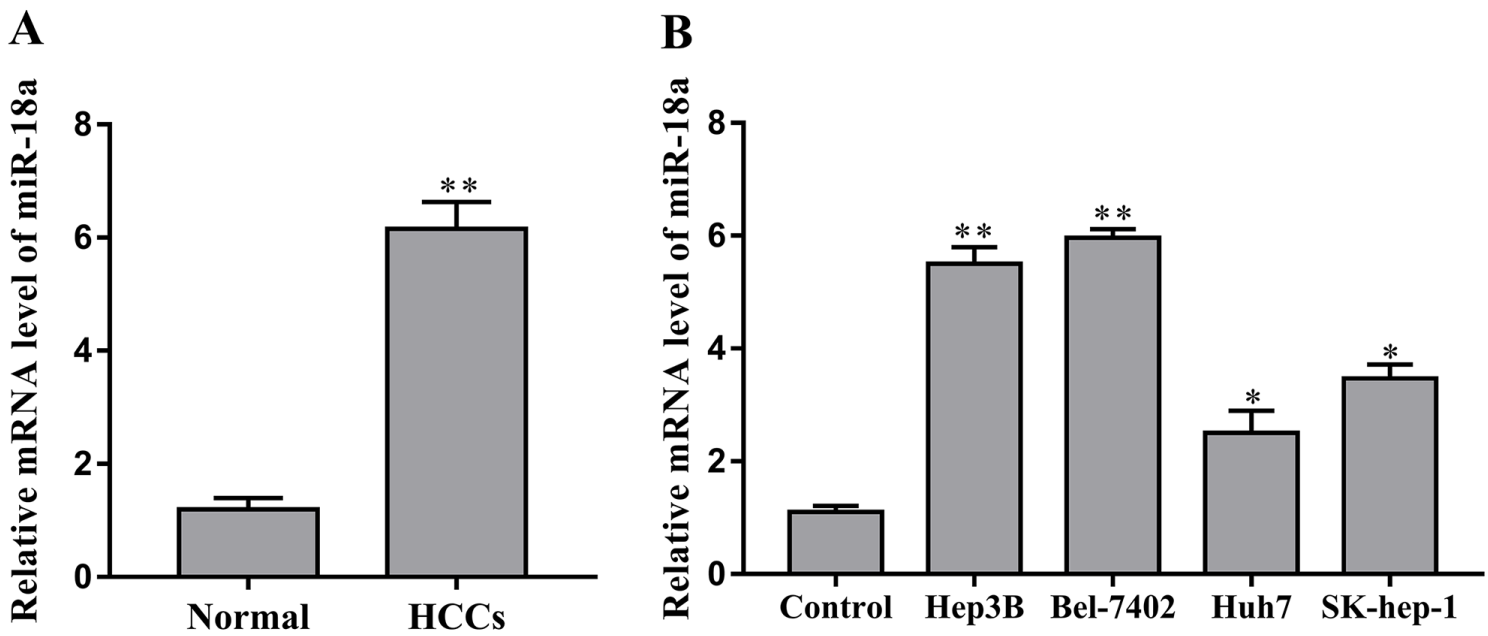

Figure 1: miR-18a is upregulated in human HCC tissues and cells. (A) The expression of miR-18a was measured in human HCC tissues and adjacent normal liver tissues (normal) by RT-PCR assay ( ${ }^{*} p<0.05$ vs. normal). (B) The levels of miR-18a were examined in human HCC cell lines Hep3B, Bel-7402, Huh7, SK-hep-1 and the normal liver cell LO2 (control) $\left(* * p<0.01\right.$, ${ }^{*} p<0.05$ vs. control). 
showed that the migration of Hep3B and Bel-7402 cell lines was significantly increased by miR-18a overexpression, but repressed by miR-18a silencing (Figure 2C). These results suggest that high levels of endogenous miR-18a may play a regulatory role in the development of HCC by promoting HCC cell proliferation and migration.

\section{KLF4 is the direct target of miR-18a in hepatocellular carcinoma cells}

KLF4 has been considered to be a tumor suppressor in HCC by previous studies [19]. To further elucidate the underlying mechanism of miR-18a regulating hepatocellular carcinoma cells, we predicted the possible targets of miR-18a using TargetScan 6.2 and miRDB databases. To further confirm whether or not this prediction is right, we performed the luciferase reporter assay in Hep3B and Bel7402 cells. The 3'-UTR regions of KLF4 containing the predicted binding site of miR-18a or the mutant site were cloned into a luciferase vector (Figure 3A). It was found that miR-18a overexpression significantly inhibited the luciferase activities of KLF4-3'-UTR-wt reporter in two cell lines, whereas miR-18a mimic transfection exhibited no inhibitory effects on the luciferase activities of KLF43'-UTR-mut reporter in cells (Figure 3B).

In addition, we confirmed that the protein level of KLF4 was strongly downregulated by miR-18a mimic, but increased by miR-18a inhibitor in Hep3B and Bel7402 cells (Figure 3C). However, there was no effect of miR-18a mimic and inhibitor on the mRNA expression of KLF4. The expression of KLF4 was negatively associated with the expression of miR-18a expression in HCC tissues (Figure 3D).

\section{miR-18a serves as a positive regulator of $\mathrm{HCC}$ cell motility by targeting KLF4}

miRNAs play a role in the regulation of cellular function by inhibiting target genes. To explore that KLF4 is indeed the downstream mediator of miR-18a in promoting hepatocellular carcinomacell motility in vitro, we employed a KLF4 plasmid to specifically induce the expression of KLF4 in cells (Figure 4A). The upregulation of KLF4 expression reversed the promoting
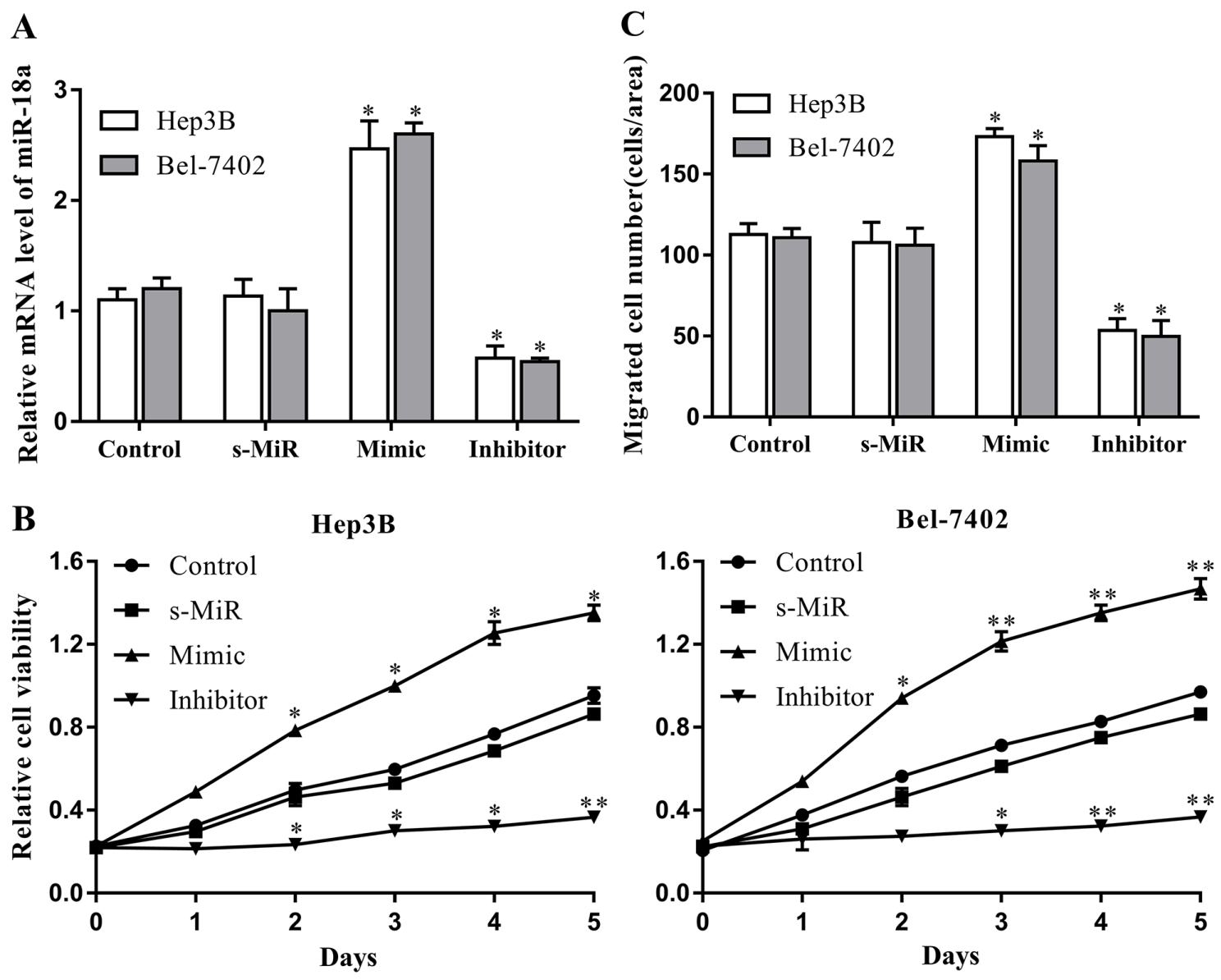

Figure 2: miR-18a promotes the proliferation and migration of human HCC cells. Cultured Hep3B and Bel-7402 cells were transfected with miR-18a mimic, inhibitor, or negative control miRNA (s-MiR). (A) The levels of miR-18a in cells were evaluated after 48 $\mathrm{h}$ of transfection using RT-PCR. (B) Cell proliferation was detected at 0-5 days via CCK-8 assays. (C) Cell migration was measured after $48 \mathrm{~h}$ of transfection by Transwell assay. Nontransfected cells were used as the control (** $p<0.01,{ }^{*} p<0.05$ vs. control). 

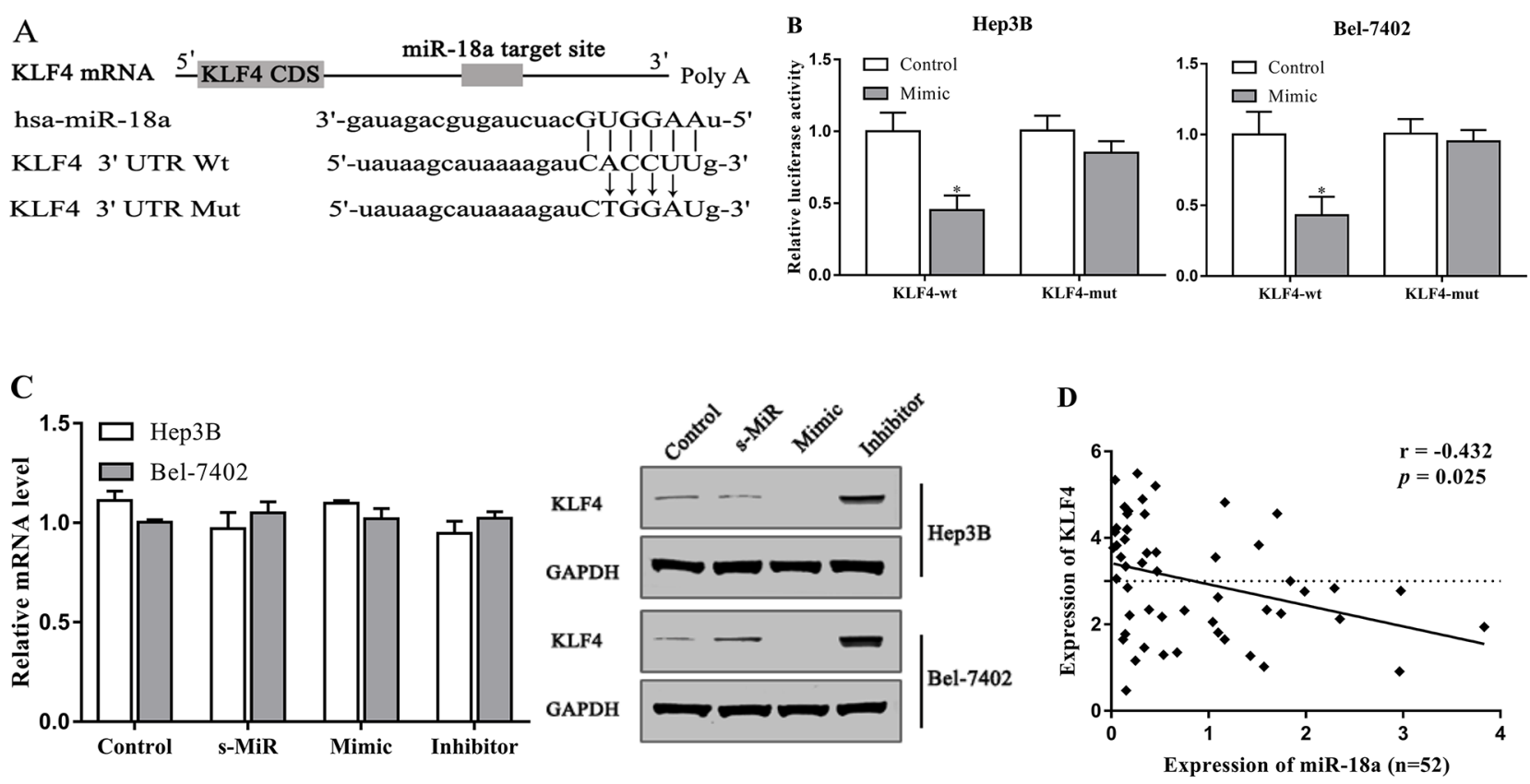

Figure 3: KLF4 is the target of miR-18a in HCC cells. (A) The predicted binding site of miR-18a in the 3'-UTR of KLF4. (B) Luciferase activities were analyzed in the cellstransfected with KLF4-3'-UTR-wt (KLF4-wt) or KLF4-3'-UTR-mut (KLF4-mut). (C) The expression of KLF4 in cells was examined via qRT-PCR and Western blot assay. (D) The expression of KLF4 was negatively associated with the expression of miR-18a expression in HCC tissues. ( ${ }^{*} p<0.05$ vs. control).
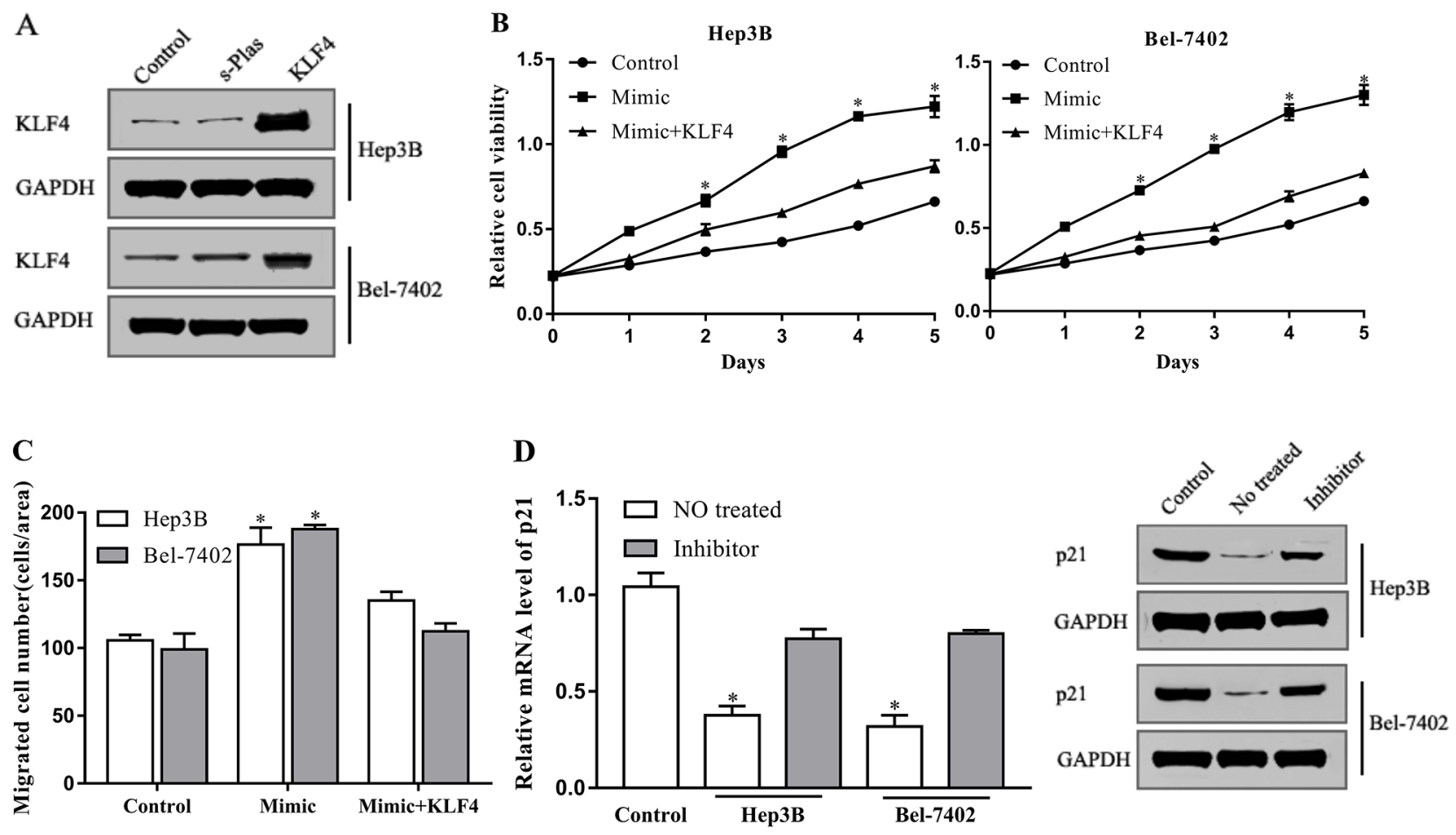

Figure 4: miR-18a increases HCC cells motility by targeting KLF4. (A) The protein levels of KLF4 were detected via Western blot in Hep3B and Bel-7402 cells transfected with KLF4 plasmid or negative control plasmid (s-Plas). After cotransfection with miR-18a mimic and KLF4 plasmid, (B) cell proliferation and (C) migration were then tested. (D) The level of p21 in Hep3B, Bel-7402, and LO2 cells (control) was measured by RT-PCR and Western blot assay. ( ${ }^{*} p<0.05$ vs. control). 
effect of miR-18a on the proliferation capacity of Hep3B and Bel-7402 cells (Figure 4B). The migration of cells induced by miR-18a mimic was also inhibited by KLF4 overexpression as shown in Figure 4C, indicating that miR-18a promotes the proliferation and migration of hepatocellular carcinoma cells by targeting KLF4.

Cell cycle inhibitor p21 is a downstream signal molecule of KLF4. Previous studies indicate that KLF4 inhibits cellular proliferation and migration by directly targeting p21 [20]. To further confirm the involvement of KLF4 in miR-18a-mediated effects, we investigated the expression of $\mathrm{p} 21$. Compared with the normal liver cell LO2, p21 expression was downregulated in Hep3B and Bel-7402 cells, whereas this inhibition was reversed by miR-18a inhibitor (Figure 4D). These findings imply that miR-18a plays a positive role in the regulation of hepatocellular carcinoma cell motility by repressing the inhibitory effect of KLF4 on cell cycle progression.

\section{DISCUSSION}

Differential expression of microRNAs in patients with hepatocellular carcinoma was reported in numerous studies, such as miR-135a, miR-33a, miR-320a, miR-122, and miR-31 [10-14]. Although over or underexpression of microRNAs occurring in $\mathrm{HCC}$ has been considered to contribute to hepatocellular carcinoma, the potential mechanism by which miRNAs regulate hepatocellular carcinoma progression needs to be further explored. Previous reports demonstrate that miRNA-18a expression is significantly upregulated in HCC and may present a novel screening biomarker for early diagnosis of HCC [17]. However, the precise role of miR-18a in the pathogenesis of $\mathrm{HCC}$ remains unknown. In the present study, we determined that miR-18a is aberrantly upregulated in HCC and promotes hepatocellular carcinoma cell motility by inhibiting KLF4, implying that miR-18a may play a positive role in the regulation of human HCC progression.

Emerging evidence indicates that cell malignant proliferation and invasion are the main causes that contribute to tumorigenesis and carcinogenesis in humans [21]. In HCC, it is reported that dysregulation of miRNAs has diverse effects on hepatocellular carcinoma cell motility. miR-765 promotes cell proliferation by downregulating INPP4B expression in human hepatocellular carcinoma [22]. Yuan et al. also reported that MicroRNA-340 is significantly downregulated in HCC tissues and can suppress the proliferation of HCC cells by directly targeting JAK1 [23]. In addition, our results revealed the positive role of miR-18a in HCC tumorigenesis. Increased expression of miR-18a increased the proliferation and migration capacity of cultured HCC cells, whereas miR-18a repression exhibited an inhibitory effect on HCC cell motility in vitro.

KLF4 is a member of KLF zinc finger transcription factor family that is enriched in a variety of tissues with a critical role in the regulation of cell differentiation and development. Accumulating evidence determined that KLF4 is expressed at a low level and exerts a tumorsuppressive effect in many types of cancer $[10,14$, 18, 19]. In HCC, KLF4 expression is also remarkably downregulated in HCC tissues compared with matched normal tissues [19]. Yao et al. reported that KLF4 has an effect as a target of miR-135a-5p on the modulation of TGF- $\beta 1$ to hepatocellular carcinoma metastasis by regulating the expression of KLF4 [10]. Here, we demonstrated that KLF4 is a direct target of miR-18a and can be inhibited by miR-18a at the posttranscriptional manner in HCC cells. Notably, we found that the overexpression of KLF4 reverses the effect of miR-18a on the proliferation and migration of HCC cells, indicating that miR-18a may increase the motility of HCC cells by directly targeting KLF4.

As the downstream target of KLF4, p21 has been identified as a negative regulator in cell cycle progression. It is reported that p21 transactivation is induced by the binding of KLF4 to its promoter, contributing to the inhibitory role of p21 in cell cycle [24]. We investigated the effects of miR-18a-KLF4 on downstream p21 in HCC cells. Compared with normal liver cell, p21 expression is significantly downregulated in cultured HCC cells, which is consistent with the findings in previous studies [25]. In contrast, miR-18a inhibitor significantly increased the expression of p21 in parallel with an enhanced KLF4 level, indicating that miR-18a may promote hepatocellular carcinoma cell growth and invasion by regulating the activity of KLF4 as well as downstream p21.

In summary, we provide a novel understanding about the pathogenesis of human HCC. Increased miR18a level plays a positive role in hepatocellular carcinoma by promoting the proliferation and migration of HCC cells through targeting downstream KLF4 and p21. This may offer an alternative therapeutic target for HCC.

\section{MATERIALS AND METHODS}

\section{Samples and cells}

Fifty-two HCC tissue specimens were collected from patients who had undergone complete surgical resection at the Department of Hepatic Surgery, the Eastern Hepatobiliary Surgery Hospital of Shanghai Second Military Medical University (Shanghai, China) between June 2015 and August 2016, immediately snapfrozen in liquid nitrogen and stored at $-80^{\circ} \mathrm{C}$. All tissue specimens (both HCC tissues and adjacent non-cancerous tissues) were constructed for experiments at the same time. Moreover, all patients provided their written informed consent and the hospital ethical committee approved the experiments.

Human HCC cell lines Hep3B, Bel-7402, Huh7 and SK-hep-1 were obtained from the Shanghai Cell Bank of 
Chinese Academy of Sciences (Shanghai, China). The liver cell line, LO2, was purchased from Li Yandong Research Group Shanghai East Hospital affiliated to Tongji University School of Medicine. Each cell line was cultured in Dulbecco's modified Eagle medium (DMEM, Invitrogen, USA) supplemented with $10 \%$ fetal bovine serum (FBS, Hyclone) as well as $100 \mathrm{u} / \mathrm{ml}$ penicillin and $100 \mathrm{ug} / \mathrm{ml}$ streptomycin. All of the cells were maintained in a humidified incubator at $37^{\circ} \mathrm{C}$ with $5 \% \mathrm{CO}_{2}$.

\section{Quantitative RT-PCR}

Trizol reagent (Invitrogen, Carlsbad, CA, USA) was used to isolate the total RNA from tissues and cells. Expression of miR-18a was measured using MicroRNA First-Strand Synthesis and miRNA Quantitation kits (Takara, Dalian, China) according to the manufacturer's instructions. CellAmp Direct RNA Prep kit for qPCR and a Protein Analysis kit (Takara) were used to detect the KLF4 and p21/CIP1 expression. The CT values of U6 and GAPDH were used as the internal control to normalize the relative expression of miR-18a and KLF4 respectively. The reaction was performed as follows: $10 \mathrm{~min}$ at $95^{\circ} \mathrm{C}$; 40 cycles of $1 \mathrm{~min}$ at $95^{\circ} \mathrm{C}, 2 \mathrm{~min}$ at $63^{\circ} \mathrm{C}, 1 \mathrm{~min}$ at $72^{\circ} \mathrm{C}$; final annealing at $72^{\circ} \mathrm{C}$ for $10 \mathrm{~min}$. The differential expression level was calculated using the $2^{-\Delta \Delta \mathrm{CT}}$ formula. All PCRs were performed in triplicate.

\section{Western blotting}

The HCC cells were lysed and extracted into protein with $1 \times$ SDS-PAGE loading buffer. Protein concentrations were determined using the BCA protein assay kit (Beyotime Institute of Biotechnology, China). Equal amounts of protein were separated on $10 \%$ SDS-PAGE gel and then transferred to the PVDF membranes. After blocking with 5\% skim milk for 2 hours, the membranes incubated with primary antibodies as follows: KLF4 (1:500, Santa Cruz Biotechnology) and GAPDH (1:3000, Santa Cruz Biotechnology).

\section{Cell transfection}

The miR-18a mimic, inhibitor, and negative control miRNA were purchased from RiboBio (Guangzhou China) and transfected into cells at $100 \mathrm{nM}$ concentrations via Lipofectamine 2000 (Invitrogen) according to the manufacturer's instructions. KLF4 plasmid (1ug; Origene, Rockville, MD, USA) was also transfected into cells in the presence or absence of the miR-18a mimic by Lipofectamine 2000. After transfection twice in $48 \mathrm{~h}$, cells were used in the subsequent experiments. RT-PCR and Western blotting were used to evaluate the transfection efficacy.

\section{Cell proliferation assay}

Cell proliferation was determined by Cell Counting Kit (CCK-8/WST-8) (Bioroot, Shanghai, China) according to the kit's instructions. Briefly, 10 ul of CCK-8 solution was added to the transfected cells that were planted in the 96-well plates $\left(5 \times 10^{3}\right.$ cells $\left./ \mathrm{ml}\right)$ at days $0-5$ and incubated for $4 \mathrm{~h}$ at $37^{\circ} \mathrm{C}$. The absorbance of cells was detected at $450 \mathrm{~nm}$ using ELISA plate reader (Bio-tek, Winooski, VT, USA).

\section{Cell migration assay}

Cell migration was measured in the Transwell Boyden chamber. Briefly, after 2 days of transfection, cells were incubated in the growth factor-free DMEM and then moved into the upper chamber of Boyden chambers coated with gelatin. The lower compartment of the chamber was filled with $600 \mathrm{ul}$ of DMEM medium supplemented with $10 \% \mathrm{FBS}$. Cells were incubated at $37^{\circ} \mathrm{C}$ for $4 \mathrm{~h}$, followed by fixation with $90 \%$ ethanol and staining with $0.05 \%$ crystal violet for $15 \mathrm{~min}$. Nontransmigrated cells were gently scraped off using cotton swab. Migrated cells were determined by counting the cells on the lower membrane surface within five fields per chamber under a microscope.

\section{Luciferase assay}

Site-directed mutagenesis was introduced into the miR-18a binding site of KLF4 mRNA using QuikChange Lightning Site-Directed Mutagenesis Kit (Stratagene). The 3'-UTR fragment of KLF4 mRNA was then subcloned into the pGL3 luciferase vector (Promega, Madison, WI, USA) by PCR method and cotransfected with miR-18a mimic into HCC cells for $36 \mathrm{~h}$ in 96-well plates using Lipofectamine 2000. Dual Luciferase Assay (Promega) was then performed to analyze the luciferase assays. Renilla (Promega) activity was used as the internal control.

\section{Statistical analysis}

All data are expressed as mean \pm SEM. The differences between groups were analyzed using SPSS 19.0 by one-way ANOVA. A value of $p<0.05$ was considered statistically significant. All experiments were performed in triplicate.

\section{ACKNOWLEDGMENTS}

This work is supported by the Science and Technology Foundation of the Health and Family Planning Commission of Guizhou province, China (gzwjkj2016-1-028).

\section{CONFLICTS OF INTEREST}

The authors declare that no competing interests exist.

\section{REFERENCES}

1. World Cancer Report 2014. http://www.who.int/hinari/ news/World_Cancer_Report_2014/en/. 
2. Chang TS, Chen CL, Wu YC, Liu JJ, Kuo YC, Lee KF, Lin SY, Lin SE, Tung SY, Kuo LM, Tsai YH, Huang YH. Inflammation promotes expression of stemness-related properties in HBV-related hepatocellular carcinoma. PLoS One. 2016; 11: e0149897.

3. Li W, Man W, Guo H, Yang P. Clinical study of transcatheter arterial chemoembolization combined with microwave ablation in the treatment of advanced hepatocellular carcinoma. J Cancer Res Ther. 2016; 12: C217-C220.

4. Di Leva G, Garofalo M, Croce CM. MicroRNAs in cancer. Annu Rev Pathol. 2014; 9: 287-314.

5. Qiu H, Zhong J, Luo L, Tang Z, Liu N, Kang K, Li L, Gou D. Regulatory axis of miR-195/497 and HMGA1-Id3 governs muscle cell proliferation and differentiation. Int $\mathrm{J}$ Biol Sci. 2017; 13: 157-166.

6. Cong F, Wu N, Tian X, Fan J, Liu J, Song T, Fu H. MicroRNA-34c promotes osteoclast differentiation through targeting LGR4. Gene. 2017; 610: 1-8.

7. Wang P, Zou F, Zhang X, Li H, Dulak A, Tomko RJ Jr, Lazo JS, Wang Z, Zhang L, Yu J. microRNA-21 negatively regulates $\mathrm{Cdc} 25 \mathrm{~A}$ and cell cycle progression in colon cancer cells. Cancer Res. 2009; 69: 8157-8165.

8. Farazi TA, Hoell JI, Morozov P, Tuschl T. MicroRNAs in human cancer. In: MicroRNA cancer regulation. Dordrecht, Netherlands: Springer. 2013; 1-20.

9. Calin GA, Croce CM. MicroRNA signatures in human cancers. Nat. Rev. Cancer. 2006; 6:857-866.

10. Yao S, Tian C, Ding Y, Ye Q, Gao Y, Yang N, Li Q. Downregulation of Krüppel-like factor-4 by microRNA-135a-5p promotes proliferation and metastasis in hepatocellular carcinoma by trans forming growth factor- $\beta 1$. Oncotarget. 2016; 7: 42566-42578. https://doi.org/10.18632/ oncotarget.9934.

11. Han SY, Han HB, Tian XY, Sun H, Xue D, Zhao C, Jiang ST, He XR, Zheng WX, Wang J, Pang LN, Li XH, Li PP. MicroRNA-33a-3p suppresses cell migration and invasion by directly targeting PBX3 in human hepatocellular carcinoma. Oncotarget. 2016; 7: 42461-42473. https://doi.org/10.18632/ oncotarget. 9886 .

12. Zhang Z, Li X, Sun W, Yue S, Yang J, Li J, Ma B, Wang J, Yang X, Pu M, Ruan B, Zhao G, Huang Q, et al. Loss of exosomal miR-320a from cancer-associated fibroblasts contributes to HCC proliferation and metastasis. Cancer Lett. 2017; 397: 33-42. https://doi.org/10.1016/j. canlet.2017.03.004.

13. Wang G, Jia T, Xu X, Chang L, Zhang R, Fu Y, Li Y, Yang X, Zhang K, Lin G, Han Y, Li J. Novel miR-122 delivery system based on MS2 virus like particle surface displaying cell-penetrating peptide TAT for hepatocellular carcinoma. Oncotarget. 2016; 7: 59402-59416. https://doi. org/10.18632/oncotarget.10681.
14. Tian C, Yao S, Liu L, Ding Y, Ye Q, Dong X, Gao Y, Yang N, Li Q. Klf4 inhibits tumor growth and metastasis by targeting microRNA-31 in human hepatocellular carcinoma. Int J Mol Med. 2017; 39: 47-56.

15. Liu WH, Yeh SH, Lu CC, Yu SL, Chen HY, Lin CY, Chen DS, Chen PJ. MicroRNA-18a prevents estrogen receptoralpha expression, promoting proliferation of hepatocellular carcinoma cells. Gastroenterology. 2009; 136: 683-693.

16. Li CL, Yeh KH, Liu WH, Chen CL, Chen DS, Chen PJ, Yeh SH. Elevated p53 promotes the processing of miR-18a to decrease estrogen receptor- $\alpha$ in female hepatocellular carcinoma. Int $\mathrm{J}$ Cancer. 2015; 136: 761-770.

17. Li L, Guo Z, Wang J, Mao Y, Gao Q. Serum miR-18a: a potential marker for hepatitis B virus-related hepatocellular carcinoma screening. Dig Dis Sci. 2012; 57: 2910-2916.

18. Zhang N, Zhang J, Shuai L, Zha L, He M, Huang Z, Wang $Z$. Krüppel-like factor 4 negatively regulates $\beta$-catenin expression and inhibits the proliferation, invasion and metastasis of gastric cancer. Int J Oncol. 2012; 40: 2038-2048.

19. Li Q, Gao Y, Jia Z, Mishra L, Guo K, Li Z, Le X, Wei D, Huang S, Xie K. Dysregulated Krüppel-like factor 4 and vitamin D receptor signaling contribute to progression of hepatocellular carcinoma. Gastroenterology. 2012; 143: 799-810.e2.

20. Xu Q, Liu M, Zhang J, Xue L, Zhang G, Hu C, Wang Z, He S, Chen L, Ma K, Liu X, Zhao Y, Lv N, et al. Overexpression of KLF4 promotes cell senescence through microRNA-203-survivin-p21 pathway. Oncotarget. 2016; 7: 60290-60302. https://doi.org/10.18632/oncotarget.11200.

21. Hanahan D, Weinberg RA. Hallmarks of cancer: the next generation. Cell. 2011; 144: 646-674.

22. Xie BH, He X, Hua RX, Zhang B, Tan GS, Xiong SQ, Liu LS, Chen W, Yang JY, Wang XN, Li HP. miR-765 promotes cell proliferation by downregulating INPP4B expression in human hepatocellular carcinoma. Cancer Biomark. 2016; 16: 405-413.

23. Yuan J, Ji H, Xiao F, Lin Z, Zhao X, Wang Z, Zhao J, Lu J. MicroRNA-340 inhibits the proliferation and invasion of hepatocellular carcinoma cells by targeting JAK1. Biochem Biophys Res Commun. 2017; 483: 578-584.

24. Yoshida T, Kaestner KH, Owens GK. Conditional deletion of Kruppel-like factor 4 delays downregulation of smooth muscle cell differentiation markers but accelerates neointimal formation following vascular injury. Circ Res. 2008; 102: 1548-1557.

25. Vaish V, Rana C, Piplani H, Vaiphei K, Sanyal SN. Sulindac and celecoxib regulate cell cycle progression by $\mathrm{p} 53 / \mathrm{p} 21$ up regulation to induce apoptosis during initial stages of experimental colorectal cancer. Cell Biochem Biophys. 2014; 68: 301-319. 